\title{
SOBRECOSTOS EN EL SERVICIO A LA CARGA AÉREA Y COMPETITIVIDAD DE LAS EMPRESAS DE COMERCIO EXTERIOR EN LIMA METROPOLITANA
}

\author{
ADDITIONAL COSTS IN AIR CARGO SERVICE AND COMPETITIVENESS \\ OF FOREIGN TRADE ENTERPRISES IN METROPOLITAN LIMA
}

\author{
Pedro L. Tito Huamaní \\ ptito18@gmail.com \\ José A. Bazán Tanchiva“ \\ jabaztan@hotmail.com
}

[RECEPCIÓN: ABRIL 2016 / CONFORMIDAD: MAYO 2016]

\section{RESUMEN}

La presente investigación tiene como objetivo revelar la existencia de sobrecostos en los servicios a la carga aérea que afecta la competitividad de las empresas de comercio exterior en Lima Metropolitana. La investigación alcanzó un nivel descriptivo y correlacional, basado en la realización de encuestas a una muestra de 119 individuos de una población total de 300 jefes de comercio exterior en Lima Metropolitana, que laboran en este tipo de empresas. La investigación nos lleva a concluir que existen serias diferencias en el modelo peruano de servicios a la carga aérea, que ocasionan que el receptor del servicio no intervenga directamente en la negociación de las condiciones de todo el servicio, debido a que la normativa peruana no define la responsabilidad del transportista hasta el punto de entrega de la mercancía al dueño de la carga, generando sobrecostos en el servicio a la carga aérea lo que influye en la competitividad de las empresas de comercio exterior en Lima Metropolitana, ya que generan condiciones de desigualdad en las relaciones comerciales entre las empresas dueñas de la carga (exportadores e importadores) y los proveedores de servicio (línea aérea, operadores de rampa y terminales de almacenamiento).

Palabras clave: Sobrecostos; carga aérea, competitividad; comercio exterior; negociación; proveedores de servicio.

\section{ABSTRACT}

This research aims to reveal the existence of additional cost in air cargo services affecting the competitiveness of foreign trade enterprises in metropolitan Lima. The investigation reached a descriptive and correlational level, based on surveys of a sample of 119 individuals out of a population

\footnotetext{
* Doctor en Ciencias Administrativas (UNMSM), Magíster en Gestión Empresarial y Licenciado en Administración (UNMSM). Docente asociado de pre y posgrado de la Facultad de Ciencias Administrativas (UNMSM). Miembro del Directorio de Investigadores de CONCYTEC-Perú.

***ic Licenciado de Administración de Negocios Internacionales, FCA - UNMSM. Maestría en Ciencias de la Gestión Económica Empresarial, FCE - UNMSM. Master Management por la Université de Bordeaux - Francia. Docente del curso de Comercio Internacional e Intraducción a la Administración, Finanzas y Negocios Globales en Universidad Privada TELESUP.
} 
of 300 heads of foreign trade in Metropolitan Lima, who work in these businesses. The research leads us to conclude that there are serious differences in the peruvian model of services to the airfreight, which cause the service receiver is not directly involved in negotiating the conditions of all the service, because peruvian law does not define the carrier's liability to the point of delivery of the goods to the owner of the cargo, generating additional costs in service to the airfreight which influences the competitiveness of foreign trade enterprises in Metropolitan Lima, as they generate conditions of inequality trade relations between the companies that own the cargo (exporters and importers) and service providers (airline, ramp operators and storage terminals).

Keywords : Additional costs; air cargo; competitiveness; foreign trade; negotiation; service suppliers.

\section{INTRODUCCIÓN}

Para nadie es un secreto que una variedad de sobrecostos en el servicio a la carga aérea encarecen y retrasan innecesariamente las operaciones de comercio exterior en el Perú, situación que afecta la competitividad del sector en su relación con los diferentes mercados internacionales, lograr identificar las fuentes de estos sobrecostos en las condiciones de competencia evidenciadas en la presente investigación es una tarea ardua. En realidad, existen varios factores que se entrecruzan lo que exige un esfuerzo de simplificación y clarificación para el análisis. Es por este motivo, que se optó por estudiar por separado cada fuente de distorsión para luego interrelacionarlos. Las fuentes de esta distorsión (que afectan al receptor del servicio) se dividieron en cinco grandes aspectos: (1) modelo actual de servicios a la carga, (2) nivel de información de los servicios a la carga, (3) volumen del comercio exterior peruano, (4) capacidad de la infraestructura aeroportuaria actual, y (5) normatividad peruana respecto a la responsabilidad del transportista (Bazán, 2014).

El análisis se centra en la premisa de que la competitividad de las empresas de comercio exterior se encuentra estrechamente relacionada con las condiciones de competencia en los mercados en los cuales se negocia los servicios a la carga que permite que las partes que negocian un contrato de servicios logren alcanzar condiciones justas y mutuamente satisfactorias.

Estudios realizados por la Defensoría del Exportador y Estudios Económicos de ADEX, dan cuenta de la existencia de sobrecostos en los servicios a la carga aérea. De igual forma, la especialista en temas aéreos Patricia Siles nos revela que una de las causas del problema son los flujos de servicios de importación y exportación por esta vía. Por otro lado, la revista Gestión Empresarial también señala la existencia de sobrecostos al comercio exterior debido al oligopolio existente entre las aerolíneas y los terminales de almacenamiento (Diario Gestión, 2011).

Esto requiere la implementación de soluciones inmediatas para no perjudicar a quienes desde hace algunos años han pasado a ser parte importante en el buen desempeño de la economía nacional, los cuales debido a la falta de aplicación de modelos y normas relacionadas al sector les genera sobrecostos o trabas innecesarias que obstaculizan su correcto desarrollo y afectan su competitividad, limitando de esta forma la obtención de beneficios derivados de los acuerdos comerciales que viene suscribiendo el gobierno en su afán por promover la inserción del país en el comercio internacional.

El comercio exterior es una actividad fundamental para el crecimiento económico de un país, es una fuente sana y permanente de generación de divisas, las cuales crean mejores niveles de ingresos y contribuyen por lo tanto al logro del bienestar colectivo de las naciones (Porter, 1998).

Uno de los aspectos más relevantes dentro de esta actividad es la Distribución Física Internacional (DFI), la cual es un conjunto de operaciones necesarias para lograr el desplazamiento de la carga desde su lugar de origen hasta el lugar donde lo requiera el dueño de la carga (exportador e importador), en el país de destino, gracias al cumplimiento del pedido en determinado espacio de tiempo y al menor costo para ambas partes. Dentro de la DFI identificamos como las operaciones más importantes y de mayor influencia los costos de transporte y almacenamiento.

El transporte permite que un producto llegue a un mercado determinado en el momento justo y en las mejores condiciones posibles. El promedio para América Latina nos dice que el 97.5\% del 
transporte se produce vía marítima, mientras que el transporte aéreo representa aproximadamente el 2.5\% de la totalidad de los medios utilizados. En el caso peruano, el transporte aéreo representa tan solo el $0.6 \%$, evidenciando la existencia de importantes factores que limitan el desarrollo de esta modalidad de servicio indispensable para la competitividad de las agroexportaciones.

Figura 1. Comercio Exterior de América Latina con resto del mundo, según Tipo de Transporte 1/(2012)

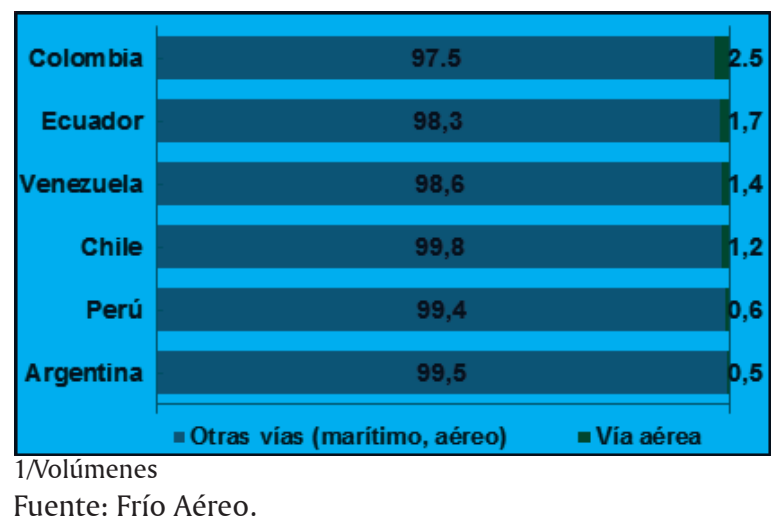

El proceso principal de la DFI, el transporte, es la actividad que más incide en el costo total de la cadena de distribución (Blocher et al., 2008). En términos generales, puede afirmarse que nuestro país paga fletes más altos que el promedio regional, lo que equivale a decir que el comercio exterior tiene en la oferta de transporte de que dispone, uno de los elementos que le impide obtener adecuados niveles de competitividad.

El modelo de servicios para el transporte, despaletización y desconsolidación de la carga, según el consenso internacional, tiene como principal característica la responsabilidad integral de la línea aérea, de modo que el transportista y el dueño de la carga negocian las condiciones de todo el servicio y el flete (Esser et al., 1994). Lo contrario ocurre en el caso peruano, donde la línea aérea asume el servicio del transporte y deja el resto del proceso en manos de los operadores de rampa y del terminal de almacenamiento. Esta diferencia en la modalidad cobra mayor relevancia dado que las condiciones para la prestación del servicio en este segundo tramo, se realiza entre el transportista y el operador del terminal sin que el receptor del servicio intervenga en la determinación de las condiciones y costos del servicio.

El almacenaje, el manejo de los palets y la consolidación/desconsolidación, son servicios que se realizan dentro de un solo proceso en un determinado lugar donde se llevará a cabo el embarque/desembarque internacional de la carga. El dueño de la carga no sabe si su mercancía fue consolidada o no con otros productos, tampoco tiene idea de si su carga constituye parte importante o minoritaria del proceso de despaletización y desconsolidación, en consecuencia, el dueño de la carga no tiene manera de asociar el costo real del servicio recibido con el precio o tarifa que ha pagado (Perdomo, 2005); de igual forma, no tiene el control del tiempo que su mercancía va a estar en el almacén.

Al comparar los costos ocasionados por la desconsolidación y almacenaje en aeropuertos cercanos o relacionados al Jorge Chávez, observamos que el costo de desconsolidación en Quito asciende a US\$ 0.03 por Kg. e incluye 7 días de almacenaje. En Chile dicho costo es de US\$0.04 por $\mathrm{Kg}$. con 3 días de almacenaje. Miami tiene un costo de US\$ 0.07 por $\mathrm{Kg}$. con 5 días de almacenaje. Y Perú, desentona con un costo de US\$ $0.32,4.7$ veces más caro que Miami y 10.7 veces más caro que nuestro cercano vecino Quito y sin derecho alguno a almacenaje.

El volumen del comercio exterior peruano es relativamente pequeño en comparación con los volúmenes de comercio que se generan en otros países de la región o en el mercado internacional en general (CEPAL, 2012). Por lo tanto, nuestro país es una especie de cliente marginal para los transportistas internacionales, hecho que limita la oferta de capacidad de carga para los exportadores e importadores peruanos. Este factor justificaría que los fletes sean más altos para las operaciones en nuestros aeropuertos.

Figura 2. Flujo de carga aérea de América Latina con resto del mundo $1 /(2012)$

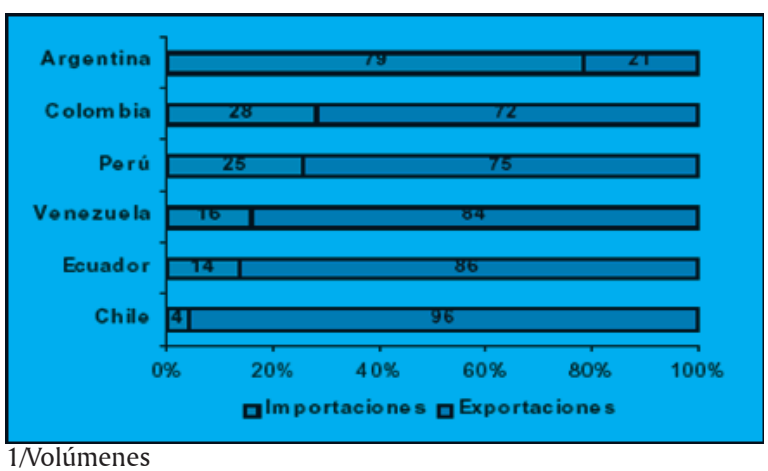

1/Nolúmenes

Fuente: CEPAL. 
En el transporte internacional, la infraestructura portuaria o aeroportuaria son la base inevitable de un monopolio. Sin embargo, esta situación es regulada mediante el diseño adecuado del contrato de concesión, un buen sistema de supervisión y mecanismos de regulación de la competencia, así como la promoción de la inversión privada en una nueva infraestructura (World Economic Forum, 2014-2015). En el caso de la concesión del aeropuerto Jorge Chávez existe una condición que hace que cerca de la mitad de los ingresos que recauda el concesionario vaya a manos del Estado. A esto se suma la demora en el cumplimiento de compromisos de inversión como la construcción de una segunda pista de aterrizaje y terminales de almacenamiento para las líneas aéreas, en donde se pueda realizar la despaletización y desconsolidación bajo la entera responsabilidad del transportista.

Figura 3. Índice de la calidad de infraestructura en carreteras $^{1}$, puertos $^{2}$ y aeropuertos ${ }^{3}$ en algunos países de América Latina

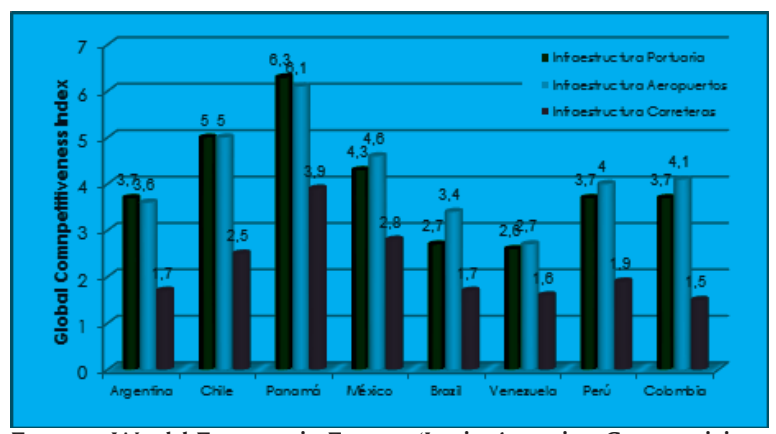

Fuente: World Economic Forum (Latin America Competitiveness Report 2014-2015)

1. Velocidad de conducción típica entre ciudades $(1=10 \mathrm{~km} / \mathrm{hr}, 7=$ $150 \mathrm{~km} / \mathrm{hr}$ ).

2. Facilidades portuarias y canales $(1=$ subdesarrolladas, $7=\tan$ desarrolladascomo la mejor del mundo).

3. Transporte aéreo ( $1=$ infrecuente e ineficiente, $7=\tan$ extendido y eficiente como el mejor del mundo).

La razón por la que el transportista y el operador del terminal pueden establecer condiciones sobre la carga excluyendo al dueño de la misma se debe principalmente a un factor normativo. La norma peruana no define la responsabilidad del transportista hasta el punto de entrega de la mercancía al dueño de la carga (Ley General de Aduanas, 2008). En tal sentido, nuestra norma no está alineada con lo que es un consenso internacional plasmado en el Convenio de Montreal de 1999, cuyo artículo 13 dice literalmente que "el destinatario tendrá derecho, desde la llegada de la carga al lugar de destino, a pedir al transportista que le entregue la carga a cambio del pago del importe que corresponda y el cumplimiento de las condiciones de transporte" (Convenio de Montreal, 1999). La normativa peruana no tiene esta condición, por eso, quien entrega la carga al destinatario es el operador aeroportuario, con una factura adicional de servicios que este último no contrató ni negoció.

Estos sobrecostos corresponden a servicios que pueden existir pero que no deben ser facturados al exportador o importador por no haber sido contratados por estos (RAP № 112, 2004); y por otro lado, a cargos que se agregan al servicio contratado (transporte y almacenaje) que ya deberían estar considerados dentro del mismo y que constituyen, en consideración de los usuarios, un abuso de posición de dominio de los proveedores de servicio en base a la integración vertical existente entre las líneas aéreas y terminales de almacenamiento.

Estos sobrecostos no se identifican en la operación aeroportuaria en forma directa. Los mismos impactan finalmente en la estructura de costos de los transportistas aéreos y en la de usuarios. Más allá de en quién impacten primariamente, estos son trasladados a los usuarios y repercuten en la competitividad del país (Segura, 1993).

En la importación, los sobrecostos impactan, por un lado, en los insumos de materias primas y bienes de capital destinados a la exportación, encareciendo las mismas y por el otro lado, en las importaciones de productos elaborados los cuales son pagados por el consumidor final. En cuanto a la exportación, estos restringen en primer lugar las operaciones, por cuanto todo incremento de costos en las transacciones provoca en la práctica una reducción del beneficio del exportador (Santa Cruz et al, 2007). Por tanto, en algunos casos el efecto práctico que estos sobrecostos tienen es impedir que el exportador realice la operación. En los casos en los cuales el exportador puede hacer la exportación, este normalmente debe hacer un ajuste a su estructura de costos de producción.

En los últimos años, a los costos implícitos en las propias ineficiencias estructurales de la prestación de los servicios de distribución, se agrega la creciente disminución de las tarifas arancelarias. El resultado lógico, es que aquellos costos implícitos en los servicios de distribución que se practican en nuestro país, son un factor determinante para la competitividad de los bienes en los mercados mundiales. 
Figura 4. Índice de Competitividad Económica 2014-2015

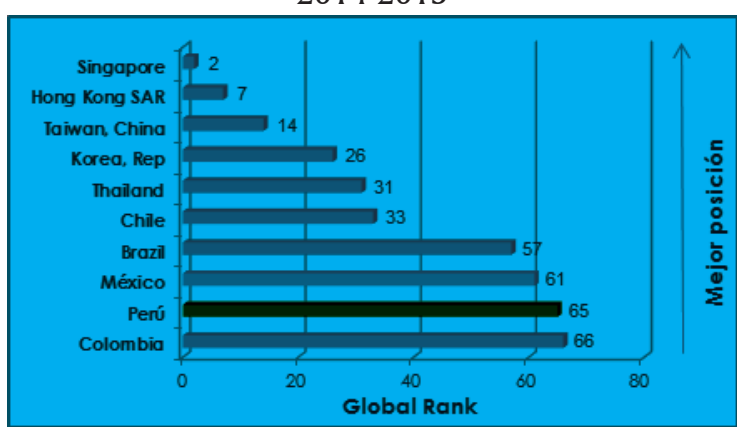

Fuente: Global Competitiveness Report, 2014-2015 (World Economice Forum -Harvard University).

Si bien los INCOTERMS establecen quien de las dos partes del contrato de compraventa internacional deberá contratar y pagar los servicios de DFI, el seguro y los impuestos aduaneros de la transacción, independientemente de quien efectivamente se haga cargo de la implementación de cada fase, el hecho es que los costos del producto movilizado entre origen y destino se termina reflejando directamente en el costo total del producto en el mercado de destino.

\section{Formulación del problema}

\section{Problema general}

¿De qué manera los sobrecostos en el servicio a la carga aérea influyen en la competitividad de las empresas de comercio exterior en Lima Metropolitana?

\section{Problemas específicos}

1. ¿De qué manera el modelo actual de servicios determina las condiciones y costos para la prestación del servicio a la carga aérea?

2. ¿En qué forma la información de los servicios a la carga aérea se asocia con el costo real del servicio recibido y el precio o tarifa pagada?

3. ¿De qué manera el volumen del comercio peruano afecta la oferta de capacidad de carga aérea para las empresas de comercio exterior?

4. ¿En qué forma la infraestructura aeroportuaria afecta el desarrollo de esta modalidad de servicio?

5. ¿De qué manera la normativa peruana respecto a la responsabilidad del transportista se relaciona con los costos en el servicio a la carga aérea?

\section{OBJETIVOS}

\section{Objetivo general}

Determinar el nivel de influencia que tienen los sobrecostos en el servicio a la carga aérea en la competitividad de las empresas de comercio exterior en Lima Metropolitana.

\section{Objetivos específicos}

1. Precisar la forma en que el modelo actual de servicios determina las condiciones y costos para la prestación del servicio a la carga aérea.

2. Establecer la forma en que la información de los servicios a la carga aérea se asocia con el costo real del servicio recibido y el precio o tarifa pagada.

3. Definir la manera en que el volumen del comercio peruano afecta la oferta de capacidad de carga aérea para las empresas de comercio exterior.

4. Determinar la forma en que la infraestructura aeroportuaria afecta el desarrollo de esta modalidad de servicio.

5. Establecer la manera en que la normativa peruana respecto a la responsabilidad del transportista se relaciona con los costos en el servicio a la carga aérea.

\section{JUSTIFICACIÓN}

Es importante el desarrollo que están experimentando las empresas de comercio exterior en el país, pues obliga a los aeropuertos a jugar un rol esencial para la salida e ingreso de las cargas de exportación e importación por vía aérea; sin embargo, la presencia de distorsiones en los servicios a la carga aérea conduce a una menor competitividad del país, ya que crea condiciones de desigualdad en las relaciones comerciales existentes entre las empresas generadoras de la carga y los proveedores de servicios.

En tal sentido, es necesario exponer como la competitividad de tales empresas se encuentra estrechamente relacionada con las condiciones de competencia en los mercados en los que se negocia los servicios a la carga, entendiéndose por condiciones de competencia aquellos que permiten a las partes que negocian un contrato de servicios lograr términos justos o mutuamente satisfactorios. 


\section{LIMITACIONES DE LA INVESTIGACIÓN}

En esta investigación no se han presentado mayores dificultades que impida su ejecución.

\section{MÉTODO}

De acuerdo a la naturaleza de los datos y de las variables en estudio la investigación se basa en un enfoque Cualitativo (Hernández, 2006), y alcanza un nivel Descriptivo - Correlacional. Es descriptivo porque en un primer momento se intenta señalar las características de los sobrecostos que señalan los Jefes de Comercio Exterior que laboran en este tipo de empresas y correlacional, porque posteriormente establecerá y sustentará la relación entre los sobrecostos en el servicio a la carga aérea y la competitividad de las empresas de comercio exterior de Lima Metropolitana.

El presente estudio reúne las condiciones necesarias para ser denominado como "Investigación Aplicada”, ya que tiene por finalidad la búsqueda y consolidación del saber, produciendo cambios inducidos y/o planificados con el objeto de resolver problemas y dirigido fundamentalmente hacia un objetivo práctico y específico.

La presente investigación tuvo el diseño de un estudio Descriptivo - Correlacional con sistemas de medición perteneciente a la clase diseño de un estudio sin intervención. La población estuvo constituida por Jefes de Comercio Exterior de 300 empresas que se dedican a actividades de importación y exportación de diversos productos no tradicionales. La técnica para la recolección de datos se dio inicialmente con la observación y posteriormente se procedió con la recolección de los datos a través de la Encuesta (Méndez, 2013), haciendo uso del instrumento de medición como el cuestionario tipo Lickert.

Los datos se analizaron e interpretaron de manera descriptiva, considerando las características que conforman las variables a estudiar. La técnica utilizada hace referencia a la Inferencia Estadística, ya que el objetivo final del análisis de datos es el de extraer conclusiones de tipo general a partir de unos pocos datos particulares. Los datos se tabularon y organizaron en cuadros unidimensionales y bidimensionales para el análisis de las variables con sus respectivas interpretaciones para lograr, posteriormente, establecer la relación entre ellas mediante las técnicas estadísticas no paramétricas.

\section{RESULTADOS}

1. Existen serias diferencias en el modelo peruano de servicios a la carga aérea, las cuales cobran relevancia debido a que el receptor del servicio (quien asume todos los costos) no interviene en la determinación de las condiciones y costos del servicio.

2. La razón por la que el transportista y el operador del terminal pueden establecer compromisos excluyendo al dueño de la carga se debe a un factor normativo, ya que la norma peruana no define la responsabilidad del transportista hasta el punto de entrega la mercancía al dueño de la carga.

3. La información imperfecta que se tiene sobre el manejo de los palets, la consolidación y desconsolidación y el almacenaje ocasiona que el dueño de la carga no tenga manera de asociar el costo real del servicio recibido con la tarifa que ha pagado.

4. El volumen actual del comercio exterior peruano, es relativamente pequeño en comparación con otros países de la región y el mercado en general, situación que determina que para las transportistas internacionales los empresarios peruanos sean considerados clientes marginales, limitando de esta forma la capacidad de carga para las exportaciones e importaciones peruanas.

5. Las deficiencias asociadas a la infraestructura aeroportuaria ocasionan un déficit en la atención de los actuales volúmenes de exportaciones e importaciones que afecta la dinámica y por ende los niveles de competitividad que viene proyectando actualmente el comercio exterior peruano.

\section{DISCUSIÓN}

El replanteamiento del modelo actual del servicio a la carga aérea en donde la línea aérea asume la responsabilidad integral del servicio, que comprende el transporte, los servicios de despaletizado y desconsolidación de la carga, cambiaría el modo en que el transportista y el dueño de la carga negocian las condiciones y costos de todo el servicio y el flete.

$\mathrm{Al}$ establecerse claramente con los proveedores el acceso a la información relacionada con el servicio a la carga (manejo de palets, consolidación/desconsolidación y almacenaje) se garanti- 
zaría al dueño de la carga la correcta asociación entre el costo real del servicio recibido con el precio o tarifa pagada y además, tendría el pleno control del tiempo que su mercancía va a estar en almacén.

El crecimiento que viene experimentando el comercio exterior peruano y el aumento de los volúmenes de exportación de perecibles, deben conducir de manera acelerada a un cambio en la oferta de capacidad de carga aérea en las empresas de comercio exterior peruano. De igual forma, la promoción de una mayor participación de líneas aéreas europeas y asiáticas, reducirían el alto nivel de concentración del servicio de transporte que se observa en las importaciones.

Las mejoras y la modernización de la infraestructura aeroportuaria, teniendo en cuenta un adecuado diseño del contrato de concesión, un sistema de supervisión, mecanismos de regulación de la competencia y la promoción de nuevas inversiones como, por ejemplo, la construcción de una segunda pista de aterrizaje, promovería el desarrollo de los servicios a la carga, ocasionando una mejora en la atención de los actuales volúmenes de exportación e importación en nuestro país.

La incorporación a la normativa peruana de las especificaciones señaladas en el Convenio de Montreal de 1999 respecto a la responsabilidad del transportista, permitiría definir la responsabilidad en la entrega de la mercancía al dueño de la carga, eliminando el costo adicional de servicios que este último no contrató ni negoció.

\section{CONCLUSIONES}

1. Los datos obtenidos como producto de la recopilación de información ha permitido precisar que el modelo actual de servicios determina las condiciones y costos para la prestación del servicio a la carga aérea, ya que el receptor del servicio (quien asume todos los costos) no interviene directamente en la negociación de condiciones de transporte y almacenamiento.

2. Se ha establecido que la falta de información en los servicios a la carga aérea (manejo de palets, consolidación/desconsolidación y almacenaje) no permite asociar el costo real del servicio recibido con el precio o tarifa pagada, lo que resulta otorgándole una clara ventaja a los proveedores del servicio en perjuicio del receptor del mismo.
3. Los datos permitieron definir que el volumen del comercio exterior peruano limita la oferta de capacidad de carga aérea para las empresas de comercio exterior, y es que en comparación con otros países de la región y el mercado en general este volumen es pequeño, lo que determina que los empresarios peruanos sean considerados como clientes marginales para los transportistas internacionales.

4. Se ha determinado que las deficiencias asociadas a la capacidad de la infraestructura aeroportuaria limitan el desarrollo de esta modalidad de servicio, ocasionando un déficit de atención en los actuales volúmenes de exportaciones e importaciones en nuestro país.

5. Se ha establecido que la normativa peruana respecto a la responsabilidad del transportista se relaciona con los elevados costos en el servicio a la carga aérea, ya que al no definir la responsabilidad en la entrega de la mercancía al dueño de la carga, se genera un adicional de servicio que este último no contrató ni negocio.

6. En conclusión, el estudio permitió determinar que los sobrecostos en el servicio a la carga aérea influyen en la competitividad de las empresas de comercio exterior en Lima Metropolitana, al crear condiciones de desigualdad en las relaciones comerciales entre las empresas dueñas de la carga y los proveedores de servicio.

\section{REFERENCIAS BIBLIOGRÁFICAS}

Bazán, J. 2014. Sobrecostos en el servicio a la carga aérea y su influencia en la competitividad de las empresas de comercio exterior en Lima Metropolitana. Tesis de Licenciado en Administración de Negocios Internacionales, Facultad de Ciencias Administrativas, UNMSM. 129 págs.

Blocher, E.; Stout, D.; Cokins, G.; Chen, K. (2008). Administración de Costos: Un Enfoque Estratégico. 4ta Edición. McGraw-Hill Interamericana Editores S.A. de C.V. México D.F. Págs. 454-474.

CEPAL. ECLAC - Latin America - Modal Split in International Transport - Year 2012. Gordon Wilmsmeier, Marc Hesser, CEPAL - United Nations.

Convenio de Montreal de 1999. Convenio sobre la Responsabilidad Civil del Transportistas 
Aéreo (Para la Unificación de Ciertas Reglas para el Transporte Aéreo Internacional), Artículo 13.

Esser, K.; Hillebrand, W.; Messner, D.; MeyerStamer, J. (1994). Competitividad Internacional de las Empresas y Políticas Requeridas: Competitividad Sistémica. Instituto Alemán de Desarrollo. Berlín.

Gestión, Diario de Economía y Negocios del Perú. Mayo 27, 2011. Pág. 17.

Hernández, R.; Fernández, C.; Baptista, P. (2006). Metodología de la Investigación. 4ta edición. McGraw-Hill Interamericana. México. Págs. 364-369.

Ley General de Aduanas (2008). Decreto Legislativo № 1053, artículo 113.

Méndez, C. (2013). Metodología: Diseño y Desarrollo del Proceso de Investigación con énfasis en Ciencias Empresariales. 4ta edición, México. Limusa 2013. Págs. 251-253.
Perdomo, A. (2005). Contabilidad de costos para la toma de decisiones. Editorial Uthea, Colombia.

Porter, M. (1998). Ventaja competitiva. Creación y sostenimiento de un desempeño superior. Editorial CECSA. México.

Regulación Aeronáutica del Perú № 112 (2004). Resolución Directoral № 030-2004-MTC-12, Sub Parte A, Sección 112.5.

Santa Cruz, A.; Coca, L. (2007). Contabilización de costos de importación y exportación. Ediciones Pacífico S.A.C. Lima - Perú.

Segura, J. (1993). Sobre Políticas Macroeconómicas de Competitividad. Papeles de Economía Española. Número 56. España.

World Economic Forum. The Global Competitiviness Report 2014-2015. Klaus Schwab, World Economic Forum. 